\section{EMBRYRIDDLE}

Aeronautical University

SCHOLARLY COMMONS
Journal of Aviation/Aerospace

Education \& Research

Volume 17

Number 2 JAAER Winter 2008

Article 1

Winter 2008

\title{
Airline Networks: A Comparison of Hub-and-Spoke and Point-to- Point Systems
}

Gerald N. Cook

Jeremy Goodwin

Follow this and additional works at: https://commons.erau.edu/jaaer

\section{Scholarly Commons Citation}

Cook, G. N., \& Goodwin, J. (2008). Airline Networks: A Comparison of Hub-and-Spoke and Point-to-Point Systems. Journal of Aviation/Aerospace Education \& Research, 17(2). https://doi.org/10.15394/ jaaer.2008.1443

This Article is brought to you for free and open access by the Journals at Scholarly Commons. It has been accepted for inclusion in Journal of Aviation/Aerospace Education \& Research by an authorized administrator of Scholarly Commons. For more information, please contact commons@erau.edu. 


\title{
AIRLINE NETWORKS: \\ A COMPARISON OF HUB-AND-SPOKE AND POINT-TO-POINT SYSTEMS \\ Gerald N. Cook and Jeremy Goodwin
}

\begin{abstract}
The disparity between the relative success of low-cost and network carriers since 2001 has often been attributed to the difference in route system architecture. This paper compares the economic and operational characteristics of point-to-point and hub-and-spoke route systems. It also argues that the emphasis placed on route structure obscures other differences in business models. Although U.S. low-cost-carriers are frequently characterized as operating point-to-point systems, few actually do so. As network airlines simplify their domestic products and the low-cost-carriers diversify theirs, the distinction between the two is rapidly fading.
\end{abstract}

\section{Introduction}

The relative success and continued growth of lowcost-carriers over the last six years contrasts sharply with the deep financial crisis and huge losses sustained by larger network carriers. This disparity has received attention in both the academic and popular press with many writers attributing the disparate fates to differences in route structure. Indeed, the terms low-cost-carrier (LCC) and point-to-point carrier are often used interchangeably. This indiscriminate terminology obscures the fact that most US LCCs do not employ point-to-point route architectures. Certainly the prototypical LCC Southwest Airlines is an example of a predominately point-to-point airline; but AirTran and Frontier, for example, operate classic hub-andspoke (H\&S) route systems. H\&S, or network, carriers American and United, on the other hand, offer nearly hourly non-stop service from New York to Los Angeles overflying their mid-continent hubs.

While route structure is a critical strategic choice, it is only one element of an airline business model and is rarely deployed in pure form. The failure to distinguish between many other aspects of the business model and route structure obscures important aspects of both. This paper seeks to clarify the contribution of route architecture to competitive advantage by contrasting the economics and operations of $\mathrm{H} \& \mathrm{~S}$ with point-to-point route systems. While interest in this discussion would usually be limited to airline and transportation economists, the relative success and prospects of airlines is a common topic for all aviation professionals. The strategic role of route architecture provides a foundation for all such discourse.

\section{History}

Prior to U.S. airline deregulation in 1978, the Civil Aeronautics Board (CAB) awarded airline operating certificates, allocated routes, and dictated ticket prices. Early air routes followed the railroad lines connecting large cities along a mostly linear structure. After World War II, the CAB certified smaller, so-called local service airlines, to provide connecting service from smaller cities previously without air service to large cities served by the established trunk airlines. Geographical coverage expanded, but required connections were often poorly coordinated, inconvenient, and usually involved one or more changes of airlines.

While attempting to balance the congressional mandate to encourage competition but avoid destructive practices, the $\mathrm{CAB}$ allowed little route competition with monopoly and duopoly common. With ticket prices set on a mileage-based formula, competition focused instead on product attributes. Although linear route systems predominated in the regulated era, some airlines gradually developed limited connecting routes. Notable are Delta and Eastern in Atlanta, United in Chicago, American in Dallas, and Allegheny in Pittsburgh (Button, 2002a).

An oil embargo, recession, and the rapid introduction of new widebody aircraft in the early 1970's resulted in plummeting loads and large losses by middecade. Pointing to the success of unregulated, profitable, intrastate airlines in California and Texas offering simple service at low prices, some academics and policy makers 
began arguing that industry regulation no longer served the public interest. The Airline Deregulation Act of 1978 freed airlines from 40 years of economic regulation (Cook, 1996).

Deregulation proponents anticipated the industry would evolve to a nation-wide linear and point-to-point route system with low, simple fares much as intrastate carriers Pacific Southwest in California and Southwest in Texas had pioneered (Bailey \& Liu, 1995). Instead, through growth, merger and acquisition, the former trunk carriers moved quickly to develop H\&S route systems in an attempt to capture the passenger from origin to destination. Many new airlines did enter service with the low-fares and pointto-point route systems as anticipated; but, in another surprise, nearly all failed. To be sure, failures also included some venerable old-line trunk carriers such as Eastern, Pan American, and Braniff, but those trunk airlines that built H\&S networks and survived the early shake-out seemed destined to dominate the industry (Borenstein, 1992). Only Southwest Airlines, expanding slowly and steadily out of its Texas base, seemed to challenge the supremacy of the H\&S concept. Southwest's low fares, frequent flights, and no frills service largely defined the low-cost airline business model.

Though the significance was unrecognized at the time, the acceptance of ticket-less travel and Internet distribution beginning in the mid-1990s was the catalysts for dramatic industry reorganization that the dot.com bubble burst and drop in demand following 9/11 only accelerated.
Since 2001, the largest airlines, now somewhat derisively labeled legacy carriers, have suffered losses of more than 40 billion dollars. Four of the six largest airlines entered bankruptcy with American avoiding the fate only by an eleventh hour concessionary agreement from its pilots. Meanwhile, Southwest was joined by JetBlue and a few other LCCs in a steady, if uneven, expansion. The contrast between these successful LCCs and the financial woes of the legacy carriers has frequently been ascribed to differences in route structure, prompting industry analysts, academic economists, and the popular press alike to declared the H\&S system, if not dead, then, seriously wounded (Legacy Carrier Challenge, 2004; McDonald, 2002; Tretheway, 2004).

Comparison of Hub and Spoke and Point-to-Point

\section{Route Systems}

Route architecture choice is the foundation of an airline's product. Point-to-point and H\&S architectures lie at the poles of a continuum with most large airlines operating some combination of the two. For clarity, however, each is discussed in its pure form as depicted in Figure 1. All passengers in a pure point-to-point system board at flight origin and deplane at the destination. In the hub and spoke system, by contrast, all passengers except those whose origin or destination is the hub, transfer at the hub for a second flight to their destination. Each has advantages best suited for certain markets which make an eventual predominance of one system unlikely.
POINT-TO-POINT

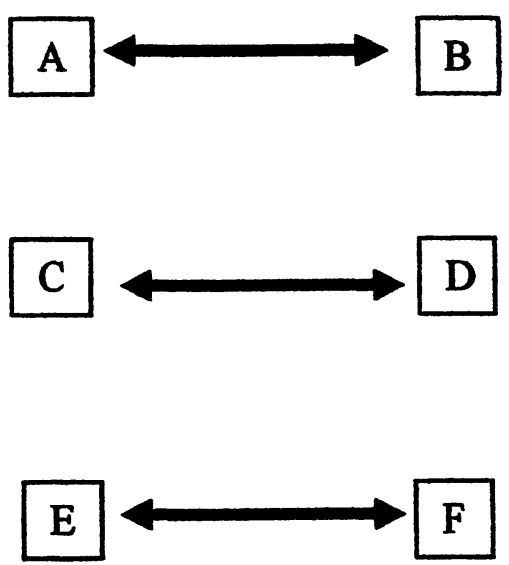

\section{HUB \& SPOKE}

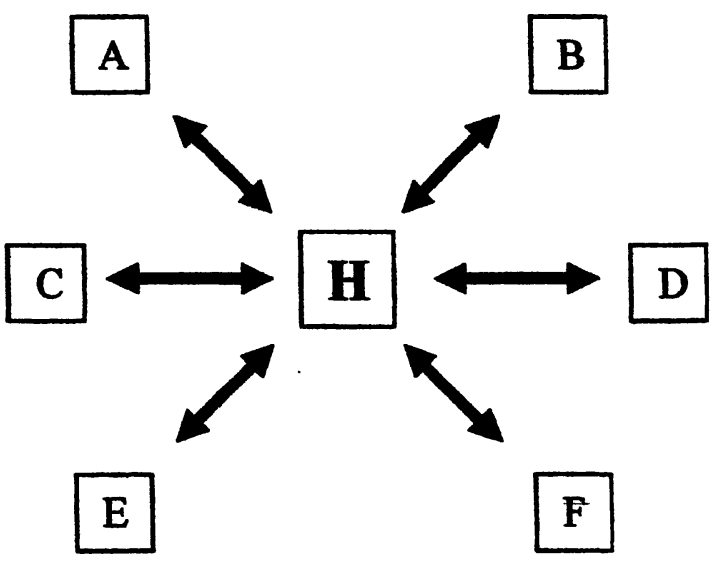

Figure 1: Point-to-Point and Hub \& Spoke Architecture 


\section{Hub and Spoke Architecture}

The H\&S route system became the postderegulation standard for a variety of reasons. The system is optimized when providing air service to a wide geographic area and many destinations. Passengers departing from any non-hub (spoke) city bound to another spoke in the network are first flown to the hub where they connect to a second flight to the destination. Thus passengers can travel between any two cities in the route system with one connecting stop at the hub, or, as one author described it, "from anywhere to everywhere" (Hansson, Ringbeck, \& Franke, 2002, p. 1.)'. Inbound and outbound flights are tightly timed and coordinated to minimize connection time (McShan \& Windle, 1989).

The H\&S system serves network destinations with the fewest routes of any alternative design. For example, five destinations require only four routes with one hub and four spoke cities but ten routes are required if the same destinations are connected with a point-to-point system. Consequently, for any given level of frequency and number of destinations, the H\&S system requires the fewest number of aircraft (Button, 2002b). With the price of mainline commercial aircraft ranging upwards of $\$ 35$ million dollars, this is a major consideration for any airline.

Large post-deregulation carriers were quick to realize the competitive advantages of expansion to more destinations and coverage area. Expansion encourages travel, increases connectivity, and improves asset utilization (Gillen \& Morrison, 2005). Following deregulation, the large airlines moved to quickly transform their route structures through growth, acquisition and merger.

\section{Anywhere to everywhere.}

The advantages of the H\&S system derive from consolidating the travel demand of each spoke city to most or all of the destinations in the network. Economic advantages increase with passenger density and network growth, positively affecting both supply and demand. Passengers prefer to use a single airline for their entire journey, so the ability to serve many cities of varying sizes confers a competitive advantage. Passengers making hub connections benefit from closely timed flights, single checkin, more convenient gate and facility locations, and reduced risk of lost baggage. Knowing that an airline likely serves a desired destination saves the passenger search and transaction costs. Familiarity with the airline's product lessens uncertainties and increases loyalty, particularly when linked to loyalty programs.

\footnotetext{
${ }^{1}$ Some itineraries in multi-hub systems require passenger connections at two hubs.
}

As destinations in the network grow and more passengers funnel through the hub, flight frequency can be increased. High frequency allows the passenger to match flights with desired itinerary times (Gillen \& Morrison, 2005); major network carriers operate ten or more connecting complexes per day. Increases in both number of destinations served and frequency also provides a bigger base over which to spread advertising and promotional expenses. A single advertisement promotes 50 destinations instead of just a few. Frequent flier programs gain utility and efficacy.

On the supply side, seat mile costs benefit from economies of traffic density. Larger aircraft can be utilized as the number of passengers per route increase; and, because seating capacity increases faster than operating and capital cost with aircraft size, seat mile costs decline. These savings allow for lower fares and/or increased margin. These economies of density and scope ${ }^{2}$ also encouraged network growth. Adding a city to the network requires only one additional route, utilizes many of the existing hub facilities, but potentially provides new service to every city in the network ${ }^{3}$. With more destinations, smaller, lower demand cities can be added that a network with fewer destinations would not support. To the extent that demand patterns of city-pairs within the network are not highly correlated, total demand is smoothed allowing better capacity utilization. For example, the summer peak east-west travel offsets a seasonal decline to winter destinations. Large network carriers dominate operations at one or more hub cities. With domination comes a degree of market power enabling the carrier to extract a fare premium on flights to and from the hub (Borenstein, 1989; US Department of Transportation, 2001). Additionally, domination provides a means to exclude new competition through control of facilities and aggressively competitive or even predatory practices (Oster, 2001).

Network growth marked the first twenty years following deregulation in a seemingly virtuous cycle of more destinations, passengers, and revenue. Each airline sought to connect all major domestic markets over one or more hubs. Later development of domestic H\&S networks

\footnotetext{
${ }^{2}$ Economies of density develop when average unit cost declines as more traffic is carried. Economies of scope arise when two or more products can be produced more cheaply together than separately.

${ }^{3}$ Some city-pairs are not practical because the distance from spoke to hub to spoke is much greater than the direct distance between the spokes, leading to unacceptable total travel time.
} 
was aided by the introduction of the regional jet in the early 1990s which provided access to destinations previously too distant for turboprop aircraft or too thin for mainline jets (Feldman, 2000). Hub growth, however, does not come without operational cost.

\section{Cost and complexity.}

Although the advantages of the H\&S system in gathering and dispersing passengers are many, the costs of operating the system are high. In the last ten years, the limits of the H\&S model have become particularly evident, and, in a reversal of earlier predictions, the foundations of the model have been questioned (McDonald, 2002). Typically about $40 \%$ of all network carrier passengers have the hub as their origin or destination. The remainder only passes through the hub(s) to make outbound connections. Extensive facilities and substantial personnel are needed solely to accommodate these connecting passengers. The passenger service agents, gates, lounges, baggage facilities, ramp and maintenance personnel dedicated to passenger connections are not necessary if flights operate non-stop between passengers' origin and destination (Donoghue, 2002). Obviously, the intervening stop at the hub requires an additional takeoff and landing incurring landing fees and facility charges.

Route system geography also drives higher cost. The hub can be directly inline with only a few origindestination markets. All other passenger itineraries require circuitous routing to the hub lengthening total flight time with attendant increase in cost. Each of the two flight segments connecting a passenger's origin and destination are shorter than a single non-stop segment. Per mile, short flight segments are more expensive to operate (Swan, 2002). Aircraft achieve lower block speeds due to additional taxi times and maneuvering for takeoff and landing. More flight time spent at lower altitudes increases fuel burn. Flight crew pay based on block time is higher as is maintenance expense because many costs are driven by flight cycle rather than flight time (Halloway, 2003).

Less obvious is the effect on utilization of spoke cities at varying distances from the hub. In order to meet the timing of next inbound bank, aircraft operating to the closer spokes must await the return of aircraft from the most distance cities. These schedule-imposed delays reduce aircraft and flight crew utilization. Scheduling techniques, particularly for carriers operating many connecting complexes, can mitigate poor utilization, but limits remain. At the hub, personnel and facilities are fully utilized during each connecting complex but lie mostly idle at other times. Asset utilization is correspondingly reduced (Berdy, 2002). At a point which depends largely on the hub airport capacity, network growth leads to rapidly escalating costs. The most obvious cause is schedule imposed hub congestion. Flight delays increase as the airport nears capacity. Arrivals and departures are limited by available runways. Inclement weather requires greater aircraft spacing, particularly for landing. Arrival rates are reduced halved at some airports - when weather permits only instrument approaches. Taxiways and gates become crowded. Terminal space, especially in older terminals, is taxed. Essentially, the hub carrier creates its own traffic congestion by scheduling ever more flights into each complex. Between connecting complexes, however, the airport may be almost empty (Franke, 2004). Airlines generally make allowance for congestion by increasing flight and connecting times, further eroding asset utilization.

The H\&S system lends itself to service of cities of greatly varying size and demand, so different aircraft models are needed to match capacity with traffic. The fleet of a large network carrier typically consists of aircraft with seating capacities ranging from 50 to 350 or more. As fleet commonality decreases, costs increase to train pilots and mechanics, inventory varied parts, and acquire and maintain fleet-specific support equipment. Aircraft and crew scheduling is more difficult and constrained as fleet complexity increases. Learning curves are more slowly exploited. These factors make the planning and management of network carriers extremely complex. Indeed, management scientists have long concentrated efforts in solving airline applications.

Finally, H\&S systems are highly susceptible to delays. A delay on one or a few inbound flights can spread as outbound flights are held for connecting passengers. Disruptions which affect the entire hub, particularly weather but also radar or computer outages, often propagate rapidly through the entire flight operation. Multiple hubs provide some opportunity for mitigation.

\section{Full service and premium pricing.}

Although effective in providing air service to varied and dispersed markets, H\&S

networks are complex and costly to operate. To earn a profit, network carriers have attempted to maximize revenues by offering a full-array of services. The high frequency and geographical scope of a network system are particularly valuable to business travelers. In return for full service, especially ticketing flexibility and seat inventory reserved for late-booking, business travelers have paid a fare premium (Lott, 2006). Excess capacity arising from the inability to match capacity with large variance in demand is offered at a substantial discount to leisure travelers. Sophisticated revenue management systems developed over 
many years exploit travelers' differing willingness and ability to pay for air travel, maximizing network revenue. Particularly in the late 1990's as network airline labor costs increased rapidly, business fares rose steadily often exceeding discount fares by a factor of ten or more. Business travelers' anger at these disparities is one factor in the traumatic restructuring of legacy carriers in the first decade of the twenty-first century (Hansson, 2002).

\section{Point-to-Point Architecture}

The counterpoint to the complexity of the H\&S system is the simplicity of point-to-point architecture which connects each origin and destination via a non-stop flight. A non-stop flight is the least expensive means to serve markets where demand is sufficient to support larger, mainline aircraft. Eliminating the intermediate stop at the connecting hub provides an average savings of more than $30 \%$ (Lott, 2005b). As compelling as this savings is, the point-to-point system offers other benefits as well.

\section{Fast and cheap.}

Point-to-point flights reduce total travel time, primarily by eliminating the intermediate stop, but also by avoiding circuitous routings and increasing aircraft block speeds. Passengers value the reduction in travel time. Without the schedule constraint of connecting complexes, aircraft turn times can be minimized. Aircraft can be utilized more fully creating an opportunity to generate more revenue. Gates can accommodate more operations per day. Airport personnel can be utilized fully throughout the day. Flight crew utilization may also increase; however, the lack of connecting flights can also complicate crew scheduling, especially in low frequency systems.

\section{Limited to largest markets.}

The inability to consolidate traffic bound for many destinations on a single flight severely limits the number of city-pairs in which non-stop flights can be economically operated. Most small and mid-sized cities have insufficient demand to support non-stop flights to more than a few, if any, destinations. Of the more than 400 US domestic airports with commercial service, less than $20 \%$ generate more than 50 directional passengers per day (Lott \& Taylor, 2004). By one estimate, only $5 \%$ of domestic city-pairs generate sufficient traffic to support non-stop service. These are also the biggest domestic markets, accounting for about $75 \%$ of all traffic and, consequently, draw intense competition (Lott, 2003). Airlines increasingly compete on the basis of price, especially in markets with an LCC presence, so yields in large markets are low (Lott, 2006). There are few, if any, opportunities remaining for LCCs to enter overpriced and underserved markets. To continue expansion, LCCs are forced into competition with each other rather than only with legacy carriers.

Low density markets might be served with smaller aircraft. One role envisioned for the regional jet was in hub bypass. Seat-mile costs for the regional jets, however, are more than twice that of LCCs operating mainline jets, usually the Boeing 737 or Airbus 320 series. The fares required to cover the operating costs of the regional jet are too high to stimulate traffic for expanded point-to-point service. Consequently, the role of the regional jet has been almost exclusively as a hub feeder to H\&S carriers (Savage $\&$ Scott, 2004). The recent failure of Independence Air is an instructive example of an attempt to operate outside of this feeder role.

Finally, demand varies significantly by time of day, week, and season making it difficult for an airline to match capacity with demand. Air travel demand in various citypairs is highly correlated, but the network carrier has some ability to off-set a drop in demand in one or more city-pairs with higher demand in others. Without connecting traffic, the point-to-point carrier has no such ability to balance route-specific demand variations; rather, it is left to changes in frequency, aircraft size, or seasonal routes in attempting to match capacity and demand. 


\section{Airline Networks}

Summary

Table 1 provides a comparison of the two route systems:

\begin{tabular}{|c|c|c|}
\hline Attribute & Hub and Spoke & Point-to-Point \\
\hline Scope & $\begin{array}{l}\text { Optimized by connecting service } \\
\text { to wide geographical area and } \\
\text { many destinations }\end{array}$ & $\begin{array}{l}\text { Each route serves a single city- } \\
\text { pair. Individual routes may be } \\
\text { dispersed. }\end{array}$ \\
\hline Connectivity & $\begin{array}{l}\text { Most passengers connect at } \\
\text { hub(s) for a continuing flight(s) } \\
\text { to destination }\end{array}$ & $\begin{array}{l}\text { No connections provided } \\
\text { (although incidental or "rolling } \\
\text { hub" connections are common) }\end{array}$ \\
\hline Dependence & $\begin{array}{l}\text { Each route highly dependent on } \\
\text { other routes for connecting } \\
\text { passengers }\end{array}$ & $\begin{array}{l}\text { Routes operate independently, } \\
\text { traffic is not affected by demand } \\
\text { from other routes }\end{array}$ \\
\hline Demand & $\begin{array}{l}\text { Varying demand in any given } \\
\text { city-pair may be offset by } \\
\text { demand from other markets }\end{array}$ & $\begin{array}{l}\text { Only varying frequency and } \\
\text { pricing available to counter } \\
\text { demand variance }\end{array}$ \\
\hline Market Size & $\begin{array}{l}\text { Efficiently serves cities of greatly } \\
\text { varying size }\end{array}$ & $\begin{array}{l}\text { Requires high density markets } \\
\text { with at least one end-point being } \\
\text { a high demand origin/destination }\end{array}$ \\
\hline Frequency & $\begin{array}{l}\text { Supports high daily frequency to } \\
\text { all destinations }\end{array}$ & $\begin{array}{l}\text { Generally lower frequency } \\
\text { depending on market type and } \\
\text { density }\end{array}$ \\
\hline Pricing & $\begin{array}{l}\text { Frequency and coverage appeal to } \\
\text { business travelers providing a } \\
\text { margin for higher business fares }\end{array}$ & $\begin{array}{l}\text { Both business and leisure } \\
\text { passengers are generally price- } \\
\text { seeking }\end{array}$ \\
\hline Asset Utilization & $\begin{array}{l}\text { Limited by network geography, } \\
\text { connection timing, and hub } \\
\text { congestion }\end{array}$ & $\begin{array}{l}\text { No network constraints on } \\
\text { utilization }\end{array}$ \\
\hline Cost of Operation & $\begin{array}{l}\text { Hub connections significantly } \\
\text { increase cost per available seat } \\
\text { mile, somewhat offset by use of } \\
\text { larger mainline aircraft }\end{array}$ & $\begin{array}{l}\text { Lowest cost per available seat } \\
\text { mile per city-pair }\end{array}$ \\
\hline Fleet Requirement & $\begin{array}{l}\text { Large range in seating capacity is } \\
\text { necessary to match capacity with } \\
\text { traffic, usually requires more than } \\
\text { one fleet type }\end{array}$ & Suited to a single fleet type \\
\hline
\end{tabular}

Table 1: Characteristics of Hub-and-Spoke and Point-to-Point Route Systems 


\section{Hybrid Systems Common}

There are, of course, hybrid and combination routes systems lying between these poles. Even Southwest's system is more accurately described as linear (Button, 2002; Lederer \& Mambinadom, 1998). Similar to a bus or train system, on a linear system, an aircraft makes several stops enroute between an origin and destination collecting and disembarking passengers at each stop. Southwest Airlines also has enough flights at its focus cities that de facto connections are widely available but not always well-timed. Thus, the linear system combines aspects of both point-topoint and H\&S architecture. All network carriers operate point-to-point flights in large markets by-passing their own hubs. JetBlue's interesting route system combines elements of the H\&S, point-to-point, and linear. These variants of route system architecture are common, but the distinction is rarely drawn.

\section{Post 2001 Developments}

Early post-deregulation development of $H \& S$ route systems included spokes to distant major cities, but much of each airline's network growth remained geographically concentrated near the carrier's home. Growth by acquisition and merger frequently eliminated what competition had previously existed (Borenstein, 1992). But inevitably, later expansion included cities already served by other carriers over their hubs. Airlines fought for market share while passengers enjoyed more and cheaper alternatives. By 2000, fourteen Midwest hubs competed for east-west travel (Capped hubs, 2001) creating intense competition for connecting, usually low-yield, traffic.

Competition from expanding LCCs, growth of Internet distribution, the emergence of ticket-less travel, the drop in demand following the Internet bubble burst, and, most acutely, the downturn following 9/11 all forced a dramatic legacy carrier restructuring over the last five years. Four carriers resorted to bankruptcy to reduce costs and increase efficiency while American and Continental were able to do so without court intervention. Common steps taken by each carrier include reduction in labor costs from concessionary agreements with labor unions or imposition where employees were not represented; retirement of older, less efficient aircraft; renegotiation of aircraft leases; reduction in product attributes such as meal and inflight services; and an increase in operational efficiencies, notably the implementation of "rolling hubs." Delta, United, and US Airways terminated their traditional defined benefit pension plans while in bankruptcy leaving the liability to the
Pension Benefit Guarantee Corporation and the taxpayer. The result is a legacy carrier group far more cost competitive with LCCs. Legacy labor cost per available seat mile, for example, has fallen from 4.4 cents in 2000 to 3.5 cents by the third quarter of 2005. This compares with 2.8 cents for the LCCs (Meehan, 2006). Cost improvements as Delta and Northwest work through bankruptcy will likely narrow this gap further.

Legacy carriers increased operational efficiencies in many ways, but one method is especially applicable to a discussion of route systems. Convenient and timely flight connections result from tightly scheduled complexes but come at the expense of poor asset utilization. American was the first to implement "depeaking" or the "rolling hub" at its Chicago O'Hare hub. Rather than closely timed arriving and departing banks, with a rolling hub flights are scheduled into and out of the hub evenly throughout the day (Flint, 2002). Because of the volume of flights, connections to all spokes are still available but connection times vary. American concluded the average passenger total trip time increased by 10 minutes but its 330 daily flights required 5 fewer aircraft and 4 less gates. Employee productivity was up 4 to $5 \%$ (Gillen \& Morrison, 2005). Mean turn-times decreased by 5 minutes at $O^{\prime} H a r e$ and 8 minutes at the spokes (Flint, 2002). Subsequently, American depeaked its Dallas and Miami hubs, as did Delta at Atlanta.

Legacy carriers have also realized, perhaps somewhat belatedly, that large and increasing price premiums extracted from business travelers in the late 1990s are no longer sustainable. Delta's introduction of Simplifares in January 2005 was generally followed by the other legacy carriers. At the time, domestic one-way coach fares were capped at $\$ 499$ dollars, far below the previous unrestricted walk-up fares which frequently exceeded $\$ 1,000$ (Lott, 2005a). The $\$ 499$ cap was still higher than the typical LCC top fare of $\$ 299$, but illustrates the necessity to compete for business travelers with competitive fares. Faced with higher fuel costs, both legacy and LCC raised the selfimposed fare caps in 2006.

Instead of following a simple business model traditionally attributed to LCCs, these carriers now differentiate their products in many ways. JetBlue raised the bar for in-flight service by providing free television. Most carriers, with the notable exception of Southwest, offer advanced seat assignment ${ }^{1}$. AirTran and Spirit have a premium or business class cabin. Service to secondary airports, long cited as a distinctive difference between LCCs 
and legacy carriers, is less widely utilized. JetBlue's home base is New York Kennedy with Boston Logan as another focus city, AirTran operates from Atlanta, and Frontier's hub is Denver. Southwest still favors secondary airports but also operates from many primary airports. Recently, it began flying from the primary airports at Denver, Philadelphia, and Pittsburgh. But LCCs are perhaps best known as point-topoint carriers. While this has always been an exaggeration, it is becoming even less true. AirTran, America West (premerger), and Frontier are predominately H\&S carriers. The smallest of the LCCs, Spirit Airlines, was the best example of a pure point-to-point carrier. Over the last year, however, it has rapidly transformed its system into a $\mathrm{H} \& \mathrm{~S}$ with Midwest and Northeast flights connecting to the Caribbean through Ft. Lauderdale. Southwest's flight schedule is not built specifically to produce connections, but connections arise because of the volume of flights at many cities. These de facto connections were termed rolling hubs before American first began "depeaking" its Chicago O'Hare hub.

\section{Conclusion}

The cost advantage once provided to LCCs by a simple point-to-point route system and product has significantly diminished. Through restructuring, legacy carriers increased efficiencies and lower labor costs. LCCs identified and exploited underserved and overpriced markets some years ago and now find themselves increasingly competing with both learner legacy carriers and other LCCs. In search of a sustainable advantage, they have ventured far from the early Southwest low-cost model introducing a variety of products. Consequently, the distinction between LCCs and legacy carriers is fading. If the new US Airways, which bills itself as the first nationwide low-cost-carrier is included, the distinction vanishes. Instead, the U.S. landscape now contains a continuum of service-price offerings with each carrier attempting to apply its strengths to one or more passenger segments. Although this variety of product offerings is consistent with marketing theory, it introduces a new complexity for observers and students of the airline industry.

Despite the importance attributed to route structure in recent years, point-to-point routes are typically not the defining characteristic of LCCs. JetBlue, which, at least until its recent reversal, was cited as major factor in the transformation of the US domestic industry, is an excellent example. Its route structure incorporates significant portions of point-to-point, $H \& S$, and linear concepts. In the midst of the industry financial crisis following 2001, many analysts would have agreed with Jay Brueckner of the University of Illinois who observed, "In the end, we'll see a mixture of low-cost, point-to-point airlines and network carriers that look a lot different." (Levins, 2004, B01). This simple bifurcation now seems less likely. Low-cost-carriers, to the extent the term still has meaning, are evolving a complex blend of route structures and product while traditional legacy carriers simplify theirs.t

Gerald N. Cook is an adjunct assistant professor of management at Embry-Riddle Aeronautical University and an Airbus A320 captain at Spirit Airlines. Over his airline career, he has held many flight operations management positions. Dr. Cook holds the Bachelor of Aviation Technology and Master of Science in Management, both from Purdue University, and the Doctor of Business Administration from Nova Southeastern University.

Jeremy Goodwin is a captain in the Delaware Air National Guard. He holds a Bachelor of Science in Civil and Environmental Engineering from Clarkson University and is a candidate for the Master of Business Administration at EmbryRiddle Aeronautical University.

The authors appreciate helpful comments from Dennis Mitchell of American Airlines. 


\section{References}

Bailey, E. \& Liu, D. (1995). Airline consolidation and consumer welfare. Eastern Economic Journal, 21(4), 463-477.

Berdy, P. (2002). Developing effective route networks. In D. Jenkins (Ed.), Handbook of airline economics ( ${ }^{\text {nd }}$ ed, pp. 119-139). New York: McGraw-Hill.

Button, K. (2002a). Debunking some common myths about airport hubs. Journal of Air Transport Management, 8, 177-188.

Button, K. (2002b). Airline network economics. In D. Jenkins (Ed.), Handbook of airline economics (2 ${ }^{\text {nd }}$ ed., pp. 27-33). New York: McGraw-Hill.

Borenstein, S. (1989). Hub and high fares: Dominance and market power in the U.S. airline industry. RAND Journal of Economics, 20(3), 344-365.

Borenstein, S. (1992). The evolution of U.S. airline competition. Journal of Economic Perspectives, 6(2), 45-73.

Capped hubs. (2001, June). Airline Business, 19(6), 57-62.

Cook, G. (1996). A review of history, structure, and competition in the U.S. airline industry. The Journal of Aviation/Aerospace Education and Research, 7(1), 33-42.

Donoghue, J. (2002, June). Hub machine. Air Transport World, 39(6), 5.

Feldman, J. (2000, October). The evolving US route map. Air Transport World, 37(10), 81-83.

Flint, P. (2002, November). No peaking. Air Transport World, 29(11), 22-25.

Franke, M. (2004). Competition between network carriers and low-cost carriers - retreat battle or breakthrough to a new level of efficiency. Journal of Air Transport Management, 10, 15-21.

Gillen, D., \& Morrison, G. (2005). Regulation, competition, and network evolution in aviation. Journal of Air Transport Management, 11, 161-174.

Halloway, S. (2003). Straight and level: Practical airline economics ( $2^{\text {nd }}$ Ed.). Aldershot: Ashgate.

Hannson, T., Ringbeck, J., \& Franke, M. (2002). Flight for survival: A new operating model for airlines. Booz Allen Hamilton, Inc. Retrieved June 27, 2006, from http://www.strategy-business.com/press/enewsarticle/22462?pg=0

Lederer, P., \& Nambimadon, R. (1998). Airline Network Design. Operations Research, 46(6), 785-804

Legacy carrier challenge: Cut cost while retaining extensive route network. (2004, April). Airline Business Report, $22(12), 1$.

Levins, H. (2004, November 7). Deregulation's real bite. St. Louis Post-Dispatch, B01.

Lott, S. (2003, June 20). U.S. major carriers will have to consolidate hubs, Mullin says. Aviation Daily, 2.

Lott, S. (2005a, January 6). Delta sees fare changes as way to win back loyalty. Aviation Daily, 4.

Lott, S. (2005b, November 2). Arrivals: Hub networks hurt by handling capacity. Aviation Daily, 24.

Lott, S. (2006, May 3). Arrivals: The incredible shrinking network airline premium. Aviation Daily, 13.

Lott, S., \& Taylor A. (2005, November 7). Hub networks hurt by handling capacity. Aviation Week \& Space Technology, $163(18), 56$ 
Airline Networks

McDonald, M. (2002, June). Endangered species. Air Transport World, 39(6), 34-36.

McShan, S., \& Windle, R. (1989). The implications of hub-and-spoke routing for airline costs. Logistics and Transportation Review, 25(3), 209-230.

Meehan, D. (2006). Aviation Industry Outlook for 2006. ASCE Air Transportation Group $9^{\text {th }}$ Annual Conference. New York. Oster, C. (2001). Predatory practices in the U.S. airline industry. U.S. Department of Transportation.

Savage, I. \& Scott, B. (2004). Deploying regional jets to add new spokes to a hub. Journal of Air Transport Management, 10(2), 147-150.

Swan, W. (2002). Airline route developments: A review of history. Journal of Air Transport Management, 8, 349-353.

US Department of Transportation. (2001). Dominated Hub Fares. 